\title{
ESPAÇOS PÚBLICOS EMBLEMÁTICOS NA FICÇÃO QUEIROSIANA
}

\section{THE EMBLEMATIC PUBLIC SETTING IN THE QUEIROSIAN FICTION}

\section{Rosane Gazolla Alves Feitosa*}

RESUMO: Por meio de alguns espaços emblemáticos na cidade de Lisboa, Eça de Queirós consegue mostrar, em sua ficção, aspectos intervencionistas dos intelectuais da Geração de 70, em que a personagem obsedante, Portugal, é problematizada em seus aspectos sociopolítico-culturais, sob o tema do constitucionalismo, do regime regenerador e sob a perspectiva das relações temporais e espaciais. PALAVRAS-CHAVE: Eça de Queirós, espaço literário, espaço público, Geração de 70, literatura portuguesa.

ABSTRACT: Through some emblematic spaces in the city of Lisbon, Eça de Queirós demonstrates in his fiction some points of intervention in the Seventies' generation of Portuguese intellectuals, in which the persistent character, Portugal, is problematized with respect to its social, political and cultural aspects, with the theme of constitutionalism, regenerating principles, and through the perspective of temporal and spatial relations

KEYWORDS: Eça de Queirós, literary setting; public setting; $70^{\text {th }}$ portuguese Generation; portuguese literature

\footnotetext{
* Professora da Faculdade de Ciências e Letras de Assis-UNESP-Univ Estadual Paulista. feitosarlc@uol.com.br
} 



\section{INTRODUÇÃO}

O realismo-naturalismo queirosiano consolidou determinados procedimentos técnico-literários, dentre os quais a supremacia da observação como procedimento metodológico de uma crítica social de tendência reformista, com orientação antirromântica e anti-idealista. $\mathrm{O}$ espaço, visto como categoria narrativa de inegáveis potencialidades de representação, seja o espaço físico, seja o social, pode ser entendido como signo ideológico.

Sob o ponto de vista do "narrar", a concepção de Lukács apresenta a descrição como um procedimento em que há uma participação, uma integração na totalidade do texto, uma necessidade e não mera "casualidade da representação de seus objetos", em que há uma "relação necessária dos personagens com as coisas e com os acontecimentos - nos quais se realiza o destino deles e através dos quais eles atuam e se debatem" (1968: 50).

Tendo em vista essas reflexões acima, nosso objetivo é comentar a presença explícita em determinados espaços públicos emblemáticos na ficção queirosiana de certos "objetos" (monumentos, edificações) (cf. MENDONÇA, 1977:10) quefuncionam comogeradores deverossimilhança, que atuam, especialmente, na caracterização do espaço narrativo nos aspectos social, econômico, histórico, em interação com outros signos, fazendo com que o espaço literário adquira uma contextura ideológica e verificar o procedimento de Eça de Queirós ao elaborar artisticamente 
a descrição, visando à proposta da Geração de 70 de produzir arte com finalidade social, à la Pierre-Joseph Proudhon - de reformar a sociedade burguesa lisboeta.

Utilizando-se da estratégia literária da descrição, com focalização onisciente e marcas de subjetividade da intromissão do narrador, consideraremos o espaço literário um paradigma do programa realista-naturalista queirosiano, ao afirmar a condição militante e interventora da criação artística; de fazer do romance o grande instrumento de análise de males sociais; de levar a cabo, de um ponto de vista reformista, uma sistemática reflexão crítica sobre a sociedade portuguesa da Regeneração, segunda metade do século XIX. Diz Bakhtin (1988: 360):

O domínio da literatura e, mais amplamente, da cultura (da qual não se pode separar a literatura) compõe o contexto indispensável da obra literária e da posição do autor nela, fora da qual não se pode compreender nem a obra nem as intenções do autor nela representadas. A relação do autor com as diferentes manifestações literárias e culturais assume um caráter dialógico, análogo às inter-relações entre os cronotopos do interior da obra.

Por meio dos textos ficcionais queirosianos, pode-se percorrer um caminho para o conhecimento dos aspectos intervencionistas dos intelectuais da Geração de 70 em que a personagem obsedante, Portugal, sob o tema do constitucionalismo e do regime regenerador, é problematizada em seus aspectos sociopolítico-culturais, na cidade de Lisboa, por meio de alguns espaços públicos emblemáticos.

Concordamos com Bakhtin (1988: 360), quando diz que

teremos os sinais visíveis, mais complexos, do tempo histórico propriamente dito, as marcas visíveis da atividade criadora do homem, as marcas impressas por sua mão e por seu espírito: cidades, ruas, casas, obras de arte e de técnica, estrutura social, etc. $\mathrm{O}$ artista decifra nelas os desígnios mais complexos do homem, das gerações, das épocas, dos povos, dos grupos e das classes sociais.

\section{ESPAÇO LITERÁRIO QUEIROSIANO}

A recriação do espaço diegético, particularmente público, que Eça de Queirós faz da capital lisboeta é vivo reflexo do sentimento decadentista em relação a seu país, que atingiu os mais representativos escritores portugueses da segunda metade do século XIX: "a obsessão da decadência nacional 
dum progressivo e inelutável declínio de todo o País, complexo de morbos, reacções, profecias e desesperos" - a miséria portuguesa. (MEDINA, 1974: 33).

A expressão "miséria portuguesa" é sugerida por João Medina, que a define como sendo um

complexo de problemas e de atitudes ideológicas diversas, às vezes antagónicas, problematização do fenómeno da decadência nacional e do pessimismo histórico que se fazem sentir duma maneira aguda nos intelectuais portugueses sobretudo a partir da segunda metade do séc. XIX. (1974: 33)

João Medina preferiu utilizar a expressão “miséria portuguesa” ao invés da "ideológica-decadentista" usada por Joel Serrão (1963, v. 2: 784-8). Situado e definido em poucas palavras, esse Portugal monárquico-constitucionalista tem sua vida sociopolítico-econômica decidida por um pequeno grupo que frequenta os bares e cafés do bairro central de Lisboa, o Chiado, o ambiente representativo da sociedade lisboeta da época: "O que um pequeno número de jornalistas, de políticos, de banqueiros, de mundanos decide no Chiado que Portugal seja - é o que Portugal é." (QUEIROZ, 1979, v. 2: 820).

Eis aqui o espaço do Portugal queirosiano, do Portugal constitucionalista, regenerador do século XIX: "Lisboa é Portugal - gritou o outro [João da Ega]. - Fora de Lisboa não há nada. O país está todo entre a Arcada e S. Bento!..." (QUEIROZ, s/d: 170). Da Arcada (situada no Terreiro do Paço ou Praça do Comércio), sede do Governo Monarquista até o Palácio de São Bento, sede do constitucionalismo - eis o resumo do Portugal contemporâneo queirosiano.

Portanto, ao percorrermos alguns dos espaços públicos de Lisboa, em que será observada a presença de "objetos" (monumentos/edificações), por meio do nosso "itinerário constitucionalista", estaremos também resgatando o espaço-tempo ficcional e histórico de Portugal.

\section{BAIXA POMBALINA: ARCADA, PRAÇA DO COMÉRCIO E ROSSIO}

Iniciaremos o nosso percurso pelos espaços públicos ficcionais queirosianos no local em que "esse século XIX português se gerou, num parto catastrófico - a Baixa Pombalina” (FRANÇA, 1980: 10).

Depois do terremoto de 1755 em Lisboa, o plano geral de reconstrução da parte central de Lisboa (1758-1763) foi desenhado e dirigido por arquitetos portugueses com a intervenção decisiva de Pombal, primeiro

ministro de D. José I. A cidade nova refletia a concepção iluminista 
que o administrador tinha do Estado. Verifica-se a preocupação com a uniformidade arquitetônica: planta geométrica, retilínea, altura igual para todos os edifícios, ausência de qualquer sinal exterior que pudesse sugerir a nobreza do proprietário. Nenhuma porta diferente, proibição de jardineiras ou vasos nas janelas. As igrejas também foram obrigadas a alinhar-se pela altura dos demais prédios.

Na praça principal da Arcada, reúnem-se as forças que para Pombal deviam formar o país: nos andares nobres, as secretarias de Estado; por baixo delas, a servir-lhes de suporte, as lojas do comércio. Do antigo paço real não ficou vestígio. O próprio nome do lugar, Terreiro do Paço, foi corrigido para Praça do Comércio.

A mudança das palavras não teve poder contra a força do hábito e a denominação de nome - de "Real" para "Comércio", "é o fato cultural e político, isto é, ideológico, mais importante do pombalismo" (FRANÇA, 1980: 11). Ao rei e à corte sobrepõe-se uma nova classe privilegiada que faz o comércio necessário ao país "em reforma", a burguesia.

Para Eça, a Baixa, onde se encontra a Arcada com a Praça do Comércio e, a alguns metros, adiante o Rossio, é sinônimo de degradação, de conservadorismo, de reduto da pequena burguesia constitucionalista. É o ambiente, o cenário, por excelência, do espaço físico de $O$ primo Basílio, tão sarcasticamente criticado por Eça, representando o descrédito do regime constitucionalista, católico e monárquico, a dissolução dos costumes, a perda da consciência nacional vigente.

O primo Basílio apresenta, sobretudo, um pequeno quadro doméstico, extremamente familiar a quem conhece bem a burguesia de Lisboa: a senhora sentimental, mal educada, [...] arrasada de romance, lírica, sobreexercida no temperamento pela ociosidade e pelo mesmo fim do casamento peninsular, que é ordinariamente a luxúria, nervosa pela falta de exercício e disciplina moral, etc., etc. - enfim, a burguesinha da Baixa. (QUEIROZ, 1979, v. 3: 517)

Pelas referências que faz à Arcada, Praça do Comércio, Rossio, Passeio Público, Rua do Ouro, Teatro D. Maria II, Rua da Madalena, Rua Nova do Carmo, Arco do Bandeira, Praça da Alegria, Aterro, dentre outras, verificadas no passeio das personagens Conselheiro Acácio e Luísa (QUEIROZ, 1979, v. 1: 1021-1025), temos uma radiografia física, social e econômica da Baixa Pombalina, com descrições que tipificam os comportamentos dissolutos e os vícios do constitucionalismo monárquico, paradigma da "miséria portuguesa". 
O Rossio, espaço público central, praça situada no centro da Baixa Pombalina, um dos espaços diegéticos recorrentes da ficção queirosiana, conota, dialeticamente, um momento passado de glória e um momento presente (segunda metade do século XIX) de decadência da nação portuguesa. O Rossio, praça construída em 1848, possui o calçamento feito de pedras, com desenhos de ondas em preto e branco, em uma referência aos mares navegados no período da expansão marítima dos séculos XV e XVI, piso este conhecido por "Mar Largo" (cf. MATOS, 1993: 855). Desse piso veio a inspiração para as calçadas brasileiras, especialmente as da praia de Copacabana na cidade do Rio de Janeiro, piso esse que, mais tarde, os emigrantes portugueses popularizaram o desenho e a maneira de assentar as "pedras portuguesas" por todo o Brasil.

Este espaço/tempo-síntese ficcional, o Rossio, constitui-se dialeticamente: convivem, de um lado, o piso desenhado pelas ondas que remetem à expansão marítima, período áureo da dinastia de Avis (1385-1580), momento de poder sociopolítico-econômico de Portugal; por outro lado, o contraste, com a estátua de D. Pedro IV (D. Pedro I, no Brasil), que instituiu de vez a monarquia constitucional em Portugal em 1834, depois de uma guerra civil com seu irmão, D. Miguel, apoiado por sua mãe, a rainha Carlota Joaquina.

Este monumento a D. Pedro IV, que faz referência ao sistema político do constitucionalismo nos textos queirosianos de ficção e de não ficção, é ironizado e desmoralizado reiteradamente como sinônimo de decadência do país, numa alusão à dinastia de Bragança e ao momento contemporâneo de Eça de Queirós.

O monumento ergue-se em formato de uma coluna coríntia com a figura de D. Pedro IV, uma estátua pedestre, simbolizando mais as virtudes cívicas do rei do que suas virtudes guerreiras. Este monumento foi erguido em 1870, no momento áureo do Cenáculo, da Geração de 70, de As farpas de Eça de Queirós e Ramalho Ortigão.

No cume da coluna, encontra-se D. Pedro IV, de uniforme de general com o manto, insígnia de realeza e a cabeça coroada de louros. Na mão direita segura a Carta Constitucional, enquanto a mão esquerda encontrase apoiada na espada. $\mathrm{Na}$ base da estrutura piramidal, em pedra de lioz, estão sentadas, nos ângulos, as figuras: Prudência, Justiça, Fortaleza e Moderação, valores que, bem analisados, expressavam exemplarmente a mundividência do constitucionalismo conservador, que acabou por hegemonizar o liberalismo português. 
A estátua, com a postura de D. Pedro, pretendia ser um símbolo de união nacional e de recalcamento da memória da guerra civil. Este monumento carrega profundas conotações ideológicas que possibilitam ao leitor perceber as ideias das personagens, a ironia do narrador intruso, funcionando como um elemento significativo na diegese.

No Rossio, também situava-se o consultório de Carlos da Maia, personagem de Os Maias e o escritório do Dr. Vaz Correia, numa esquina para a Rua do Ouro, onde, dois anos depois de sua formatura, clinicava Alípio Abranhos, o futuro Conde de Abranhos, personagem de $O$ conde de Abranhos.

Em O primo Basílio (1979) encontramos este excerto realista, enfatizando a decadência do povo português e o sistema de governo - o constitucionalismo. Pode-se concretizar esta decadência pelo conjunto: Rossio, logradouro central da capital de Lisboa e a estátua de D. Pedro IV, símbolo de um constitucionalismo falhado, ambos situados na Baixa Pombalina.

No Rossio, sob as árvores, passeava-se; pelos bancos, gente imóvel parecia dormitar; aqui e além pontas de cigarro reluziam; sujeitos passavam, com o chapéu na mão, abanando-se, o colete desabotoado; a cada canto se apregoava água fresca do Arsenal; em torno do largo, carruagens descobertas rodavam vagarosamente. $O$ céu abafava - e na noite escura, a coluna da estátua de $D$. Pedro tinha o tom baço e pálido de uma vela de estearina colossal e apagada (v. 1, cap. IV: 927). 


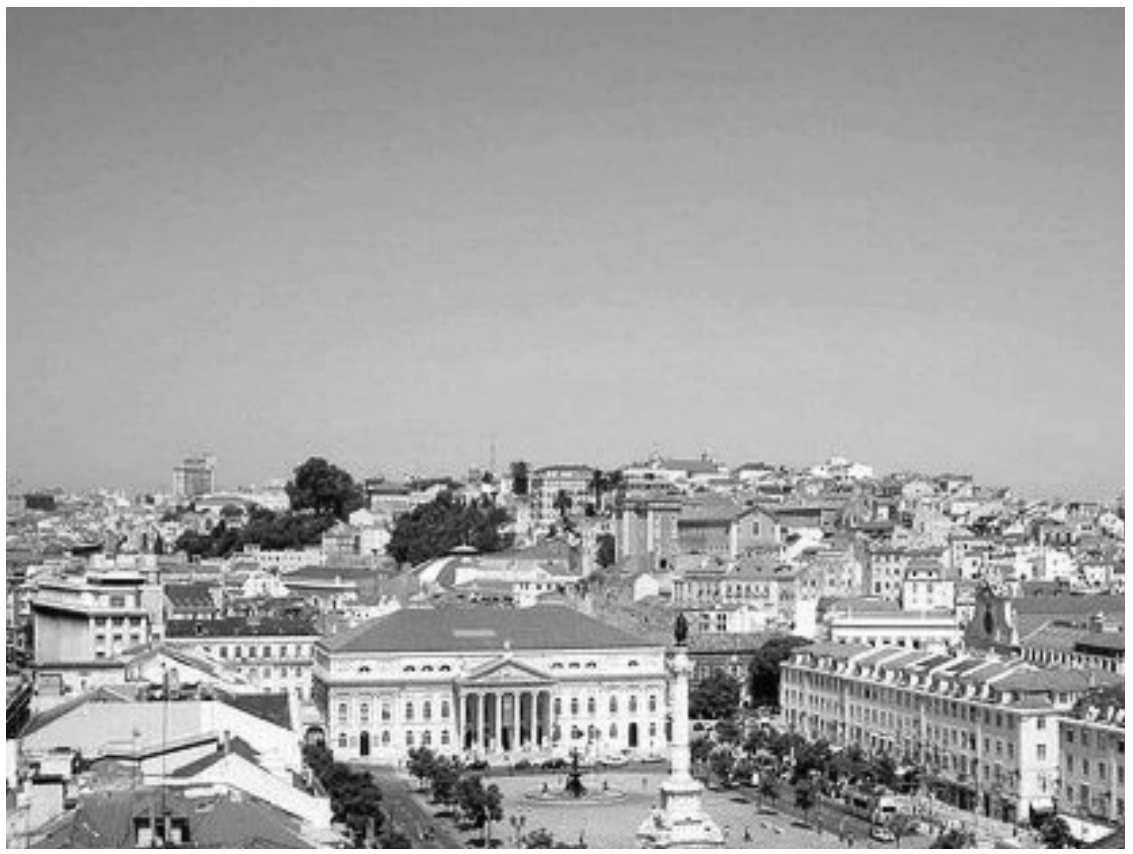

http://farm1.static.flickr.com/115/286238408_fbadd05bee.jpg?v=0

Vossa Majestade está no alto de uma coluna, esguia, polida e branca como uma vela de estearina, e mostra, equilibrando-se sobre uma bola de bronze, um papel, a Carta - ao clube do Arco do Bandeira. [...] Vossa Majestade está com a espada na bainha. Vossa Majestade passa à posteridade com um rolo de papel na mão - como um tabelião, ou um vate. Nada que lembre o soldado. É uma estátua - doméstica. (Uma campanha alegre, v. 3: 1246)

Um espaço público fechado, em que é imperativa a frequência, tanto por parte da nobreza, quanto da burguesia, é o Teatro de S. Carlos - local de "exibição do eu".

Criado em 1793, no centro da nova cidade burguesa, no atual Largo do Chiado, como um teatro da corte para a burguesia, que Pombal favorecera e passara os seus capitais à nova situação régia. $\mathrm{O}$ teatro nascia da aspiração dos grandes negociantes a espaços e instrumentos de sociabilidade, deixando evidenciar vários aspectos: político - o nome do teatro evoca Carlota Joaquina, mulher do príncipe real, futuro D. João VI; social - o caráter cívico da iniciativa destinada a dotar Lisboa duma sala pomposa 
que marcava o poder da classe construtora, a burguesia; estético - o estilo (neoclássico) escolhido na sequência daquele que a Lisboa pombalina esboçara e que agora assumia teor erudito. "Escapara [Papá Monforte] aos cruzados ingleses, arrancara uma fortuna da pele do africano, e agora rico, homem de bem, proprietário, ia ouvir a Corelli a S. Carlos." (QUEIROZ, s/d: 25).

Note-se que o nome do teatro - São Carlos - evocando a nobreza, em nome da mulher de um futuro rei, retoma o princípio que fizera erguer a estátua equestre do rei D. José I, no centro duma praça dita do Comércio (da burguesia). O teatro fora erguido pela burguesia, mas recebia um nome que homenageava a nobreza.

Podiam ir ao teatro, esta noite. [...] foi buscar o Jornal do Comércio sobre a mesa, olhou os anúncios:

- Podiam ir a S. Carlos, que acaba mais tarde... É o Fausto [...].

- Eu vou buscar o camarote. Uma boa frisa, hem?... Uma frisazinha ao pé do palco. De que lado era a frisa? Dezoito. Perdiam a vista da família real, era pena!... (O primo Basílio, v. 1: 1122-1123, 1125)

A sua arquitetura interna típica dos teatros italianos, de corte do século XVIII, favorecia a "exibição do eu", tanto na sala como no palco. Não obstante, a reforma teatral do setembrista (1836), a que se ligou o nome de Garrett, este modelo de "exibição do eu", não só prevalece como até se reforça durante o constitucionalismo.

quando Lisboa descobriu aquela legenda de sangue e negros, o entusiasmo pela Monforte calmou [...] Quando ela [Maria Monforte] aparecia agora no teatro, D. Maria da Gama afetava esconder a face detrás do leque, porque lhe parecia ver na rapariga [...] o sangue das facadas que dera o papàzinho! [...]

Depois, daí a duas semanas o Alencar, entrando em S. Carlos ao fim do primeiro acto do "Barbeiro", ficou assombrado ao ver Pedro da Maia instalado, à frente, ao lado de Maria. [...].

Nunca Maria Monforte aparecera mais bela: tinha uma dessas toilettes excessivas e teatrais que ofendiam Lisboa [...].

O Alencar foi observar "o caso" do camarote dos Gamas [...].

O Alencar correu ao Marrare, de braços ao ar, a berrar a novidade. (QUEIROZ, s/d: 25-26) 
Durante o período romântico, segundo a periodização (1835-1885) de José-Augusto França (1990), o Teatro de S. Carlos foi uma espécie de "Passeio Público" com cúpula, onde o verdadeiro espetáculo ocorria na sala e não no palco.

Pode-se dizer que o espaço público do Teatro de São Carlos está presente em quase toda a ficção queirosiana. Se cotejarmos o período de sua construção (1793), e todo o seu período áureo de existência no século XIX, considerado como o local por excelência para servir de "vitrine" à sociedade lisboeta constitucionalista, veremos que a história do Teatro caminha paralela à formação da família Maia, de acordo com a diegese do romance Os Maias, partindo de Caetano de Maia (fins do século XVIII), passando por Afonso (10 "tempo" - Vintismo), por Pedro da Maia (2。 "tempo" - reinado de D. Miguel - 1828 à Regeneração - 1851) e por Carlos da Maia (30 "tempo" - Regeneração - 1851 a 1887 - fim cronológico da narrativa de Os Maias). O Teatro de São Carlos foi simbólico da sociedade lisboeta do século XIX.



http://farm2.static.flickr.com/1395/804112060_4d57532f2b.jpg?v=0. Acesso em: 23 abr. 2009. 
Demonstra-se, desse modo, que o espaço público da narrativa queirosiana, seja aberto ou fechado, é "Portugal em ficção", é seguidor dos preceitos realistas-naturalistas apregoados desde as Conferências do Cassino: "É no realismo que se pode fundar a regeneração dos costumes" (SALGADO JR, 1930: 58). Com a ficção caminhando ao lado da realidade, Eça de Queirós vai mostrando a degradação da pátria, que para ele ocorreu após o constitucionalismo, a decadência moral, social, política, econômica, para "tentar-se a regeneração dos costumes pela arte" (op.cit.).

Com este propósito, tentam se aproximar o mais "realisticamente" possível do espaço português, para que fiquem claros e expostos os "males" que Eça e sua Geração de 70 pretendiam extirpar, a fim de levar o país ao "progresso", entendendo-se este como referente à situação em que se encontravam os países europeus, não os da Península, Espanha e Portugal, mas, principalmente, a Inglaterra, França, Alemanha.

Ainda que o Teatro fosse o local privilegiado de representação oficial da família Real, e de todo o "Grand Monde" lisboeta, Eça de Queirós ataca-o violentamente, mostrando a decadência tanto do público que o frequentava - física, moral e cultural; quanto do aspecto físico do ambiente. Evidencia, acentuadamente, a degradação da geração portuguesa constitucionalista, seguindo a trilha de sua obsessão decadentista.

E o Conselheiro declarou que Lisboa só era imponente, verdadeiramente imponente, quando estavam abertas as câmaras e S. Carlos! (O primo Basílio, v. 1: 933-934)

Passava das oito horas quando o trem parou em S. Carlos. Um gaiato, que tossia muito, com o casaco pregado sobre o peito por um alfinete, precipitou-se a abrir a portinhola; e D. Felicidade sorria de contentamento, sentindo a cauda do vestido de seda arrastar sobre o tapete esfiado, do corredor das frisas. [...]

Tinham desenhado, com um charuto apagado sobre a parede caiada, enormes figuras obscenas; e alguém [...] ajuntara por baixo as designações sexuais com a boa letra cursiva.

E Jorge revoltado:

- [...] Isto só em Portugal!... [...]

Acrescentou com bonomia: - São rapazes, com o charuto. Apreciam muito esta distração... E sorrindo, recordando-se: - Uma ocasião mesmo, o conde de Vila Rica, que tem graça, insistiu comigo, dando-me o charuto, para que eu fizesse um desenho... [...] tomei o charuto e escrevi com mão firme: HONRA AO MÉRITO!" (O primo Basílio, v. 1: 1127-1132) 
Na platéia, nas bancadas clareadas, sujeitos quase deitados namoravam com languidez; [...] D. Felicidade interessava-se por duas espanholas de verde, que na parte superior imobilizavam, numa afetação casta, os seus corpos de lupanar.

Luísa então viu D. Felicidade perturbar-se; e seguindo o eu olhar negro, subitamente avivado, descobriu na geral a calva polida do Conselheiro Acácio - que cumprimentava, prometendo generosamente, com a mão espalmada, a sua visita próxima.

- Veio, apenas o pano desceu; e felicitou-as imediatamente por terem escolhido aquela noite: a ópera era das melhores e estava gente muito fina. Lamentou ter perdido o primeiro acto; - ainda que não gostasse extremamente da música, apreciava-o por ser muito filosófico. E, tomando da mão de Luísa o binóculo, explicou os camarotes, disse os títulos, citou as herdeiras ricas, nomeou os deputados, apontou os literatos.

- Ah! Conhecia bem S. Carlos! Havia dezoito anos! (O primo Basílio, v. 1: 1129).

No percurso do nosso itinerário constitucionalista, em função dos espaços públicos na ficção queirosiana, partimos do Terceiro Paço com a sua Arcada e a estátua de D. José I e chegamos até à estatua de Camões, na Praça Camões, no antigo Largo do Loreto, hoje Largo do Chiado (desde 1925). 


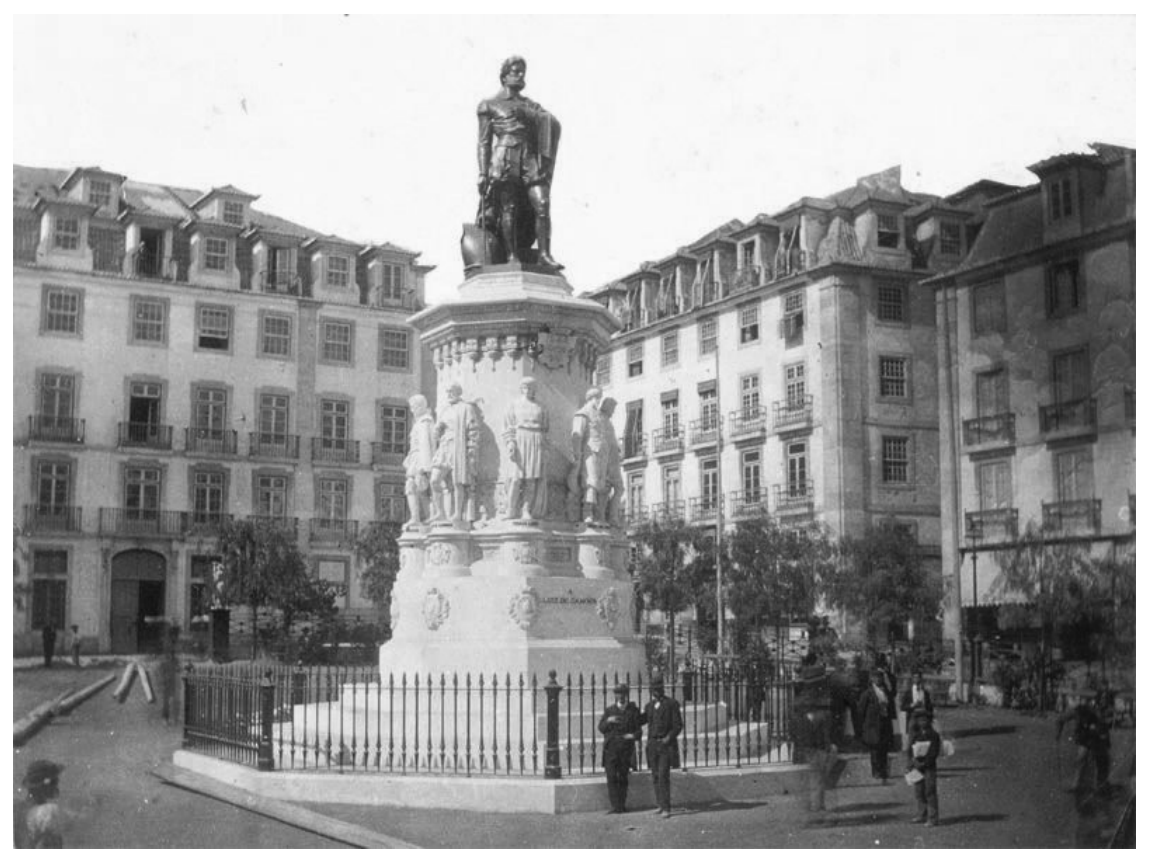

http://purl.pt/93/1/iconografia/os_maias/ea126v_ft1_3.jpg. Acesso em: 23 abr. 2009.

A presença da figura de Camões, não do poeta de Os Lusíadas, mas do símbolo maior da pátria que cristaliza em torno do seu nome, da sua epopeia e da sua lenda, as virtualidades regeneradoras de Portugal, a sua imagem ideológica e não a imagem literária, esteve sempre presente na ficção queirosiana, ora explícita, ora invisível.

A imagem camoniana vem crescendo na ficção queirosiana desde $O$ crime do Padre Amaro (versão definitiva) e chega até Os Maias, para ocupar um lugar de destaque, um "local de alerta" no espaço dos romances de Eça de Queirós. A importância da figura ideológica de Camões é particularmente significativa se a enquadrarmos nos problemas e nas preocupações do seu tempo - segunda metade do século XIX - momento histórico da Regeneração de Portugal.

A estátua de Camões, destacada nos espaços públicos ao longo das narrativas de Eça, funciona como um objeto/objeto-arte, símbolo da decadência da pátria, apesar de Camões conotar um momento da grandeza de Portugal. 
Nas oito figuras da estátua, note-se o predomínio dos "cronistas e dos poetas heróicos da pátria antiga", homens de letras cuja função é narrar a gesta nacional, desde a consolidação da nacionalidade operada pelo mestre de Avis até o declínio do Império português do Oriente. Eça talvez pensasse neste detalhe quando realçou no monumento sua função de "memória quase perdida", de rememoração duma glória passada nacional em todos os seus aspectos.

O desfecho de O crime do Padre Amaro (1880), que precede de perto o ínicio da elaboração de Os Maias (1888) e faz eco na composição de $A$ capital, apresenta um quadro de decadência e rebaixamento nacionais em contraste com a exclamação do conde de Ribamar, sintetizada em:

- Que paz, que animação, que prosperidade!

- [...] não admira realmente que sejamos a inveja da Europa! (O primo Basílio, v. 1:369).

Ao discurso grandiloquente e oco do conde de Ribamar acerca da realidade portuguesa, Eça contrapõe o quadro realista do país real, contrastando com o espaço envolvente do largo de Camões.

Tipóias vazias rodavam devagar, pares de senhoras passavam, de cuia, cheia e tacão alto, com os movimentos derreados, a palidez clorótica duma degeneração de raça; nalguma magra pileca, ia trotando algum moço de nome histórico, com a face ainda esverdeada da noitada de vinho; pelos bancos da praça gente estirava-se num torpor de vadiagem; um carro de bois, aos solavancos sobre as suas rodas, era como símbolo de agriculturas atrasadas de séculos; fadistas gingavam, de cigarro nos dentes; algum burguês enfastiado lia nos cartazes o anúncio de operetas obsoletas; nas faces enfezadas de operários havia como a personificação das indústrias moribundas... (O primo Basílio, v. 1: 369)

\section{CONSIDERAÇÕES FINAIS}

A importância do espaço na estruturação do texto ficcional queirosiano é percebida como elemento integralizador, na medida em que provoca no leitor a sensação de autenticidade da sua ficção proposta pelo Realismo. Para isso, Eça de Queirós buscou, dentre outros procedimentos narrativos, a descrição dos espaços nos quais ocorre a diegese, com o objetivo de mostrar que o espaço físico não é meramente gratuito ou estético: ele 
motiva o diálogo, dinamiza a ação, liga-se à vida das personagens, estabelece uma correlação íntima com a movimentação, projeta-se, muitas vezes, no comportamento e estado de espírito das personagens.

Portanto, por meio do ato estético do narrar, Eça de Queirós faz uma crítica virulenta e sarcástica do período da Regeneração em Portugal, ao mostrar a radiografia social do país tal qual fizera o constitucionalismo desde 1820; ao utilizar a descrição particularizada de espaços públicos da capital, Lisboa, como parte integrante/complementar da forma de narrar, espaço este paradigmático de uma classe social, de um tempo sociopolíticocultural e de uma mentalidade, para se ter a necessária compreensão dos maquinismos sociais subjacentes ao espetáculo do cotidiano lisboeta.

\section{REFERÊNCIAS BIBLIOGRÁFICAS}

BAKHTIN, Mikhail. Questões de literatura e de estética: a teoria do romance. Trad. Aurora F. Bernardini e outros. São Paulo: FUNDUNESP; HUCITEC, 1988.

FRANÇA, José-Augusto. A arte em Portugal no século XIX. Lisboa: Bertrand, 1990. $2 \mathrm{v}$.

FRANÇA, José-Augusto. O romantismo em Portugal: estudo de factos socioculturais. 2. ed. Lisboa: Livros Horizonte, 1993.

FRANÇA, José-Augusto. Perspectiva artística da história do século XIX português. Análise Social, Lisboa, n. 61, p. 9-27, 1980.

LUKÁCS, Georg. Narrar e descrever. In: LUKÁCS, Georg. Ensaios sobre literatura. 2. ed. Coord. e pref. Leandro Konder. Rio de Janeiro: Civilização Brasileira, 1968. p. 47-99.

MATOS, A. Campos (Org. e Coord.). Dicionário de Eça de Queiroz. 2. ed. rev. e aum. Lisboa: Caminho, 1993.

MEDINA, João. Eça político. Lisboa: Seara Nova, 1974.

MENDONÇA, Aniceta de. Da descrição aos objetos-personagens nos romances de Eça de Queiroz. Revista de Letras, Assis, v. 19, p. 9-37, 1977. 
QUEIROZ, Eça de. Obras de Eça de Queiroz. Porto: Lello \& Irmão, 1976$9.4 \mathrm{v}$.

QUEIROZ, Eça de. Os Maias: episódios de uma vida romântica. Fixação do texto e notas de Helena Cidade Moura. Lisboa: Livros do Brasil, s/d. SERRÃO, Joel. Decadência. In: SERRÃO, Joel (Dir.). Dicionário de Portugal. Lisboa: Iniciativas Editoriais, 1963. v. 2, p. 784-8. 